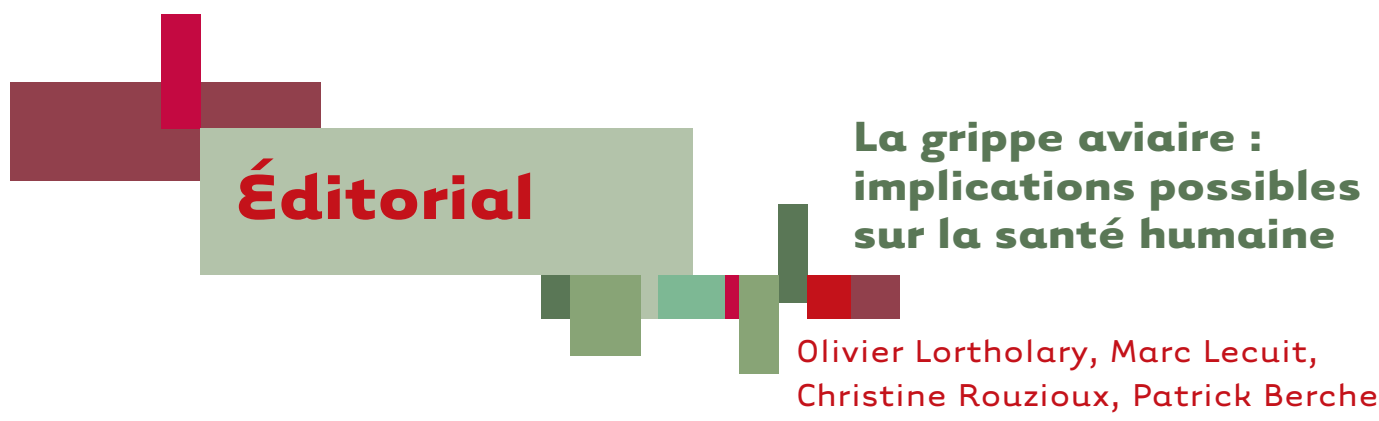

> L'enjeu majeur du contrôle de l'épizootie grippale aviaire actuelle due au virus $\mathrm{H} 5 \mathrm{Nl}$ est la prévention d'une nouvelle pandémie grippale humaine. Celle-ci pourrait être liée à : (1) un réassortiment du génome de ce virus aviaire avec une souche épidémique humaine entraînant la circulation d'un virus hybride exprimant des antigènes viraux aviaires mais capable d'infecter une population humaine n'ayant pas d'immunité préexistante à ce nouveau virus; ou (2) à la transmission interhumaine d'un virus aviaire ayant acquis directement un tropisme humain. Le propos de cet Editorial est de préciser sous forme de quelques questions/réponses les implications possibles sur la santé humaine des virus grippaux aviaires et notamment du virus responsable de l'épizootie aviaire actuelle, le virus $\mathrm{H} 5 \mathrm{Nl}$ [1-9].

\section{Que sont les virus aviaires?}

Les virus grippaux sont des virus à ARN de la famille des Orthomyxoviridae dont le génome est composé de huit segments. Trois espèces de virus influenzae existent : influenza $A, B$ et $C$. Les virus $A$ comportent plusieurs sous-types définis par des antigènes de surface que sont l'hémagglutinine $(\mathrm{H})$ et la neuraminidase $(\mathrm{N})$ dont il existe respectivement 15 et 9 types. Ils sont responsables des infections humaines et de celles de plusieurs espèces aviaires ou de mammifères, notamment le porc. Les virus aviaires domestiques sont principalement de sous-types $\mathrm{H} 5$ et $\mathrm{H} 7$. Ils ne sont pas tous hautement pathogènes, c'est-à-dire capables d'induire une létalité voisine de $100 \%$ chez les espèces aviaires qu'ils infectent, mais la présence d'un virus $\mathrm{H} 5$ ou $\mathrm{H} 7 \mathrm{chez}$ les volailles est toujours préoccupante, compte tenu de la létalité potentielle que ces virus peuvent induire dans les élevages. Leur pathogénicité est en partie liée à la présence d'acides aminés basiques (arginine et lysine) au site de clivage de l'hémagglutinine $(H)$, qui est la protéine majeure contrôlant l'adhésion et l'entrée du virus dans les cellules. Le clivage de l'hémagglutinine est une étape clé pour l'internalisation virale et la susceptibilité de cette protéine aux protéases cellulaires est donc déterminante pour le tropisme et la virulence du virus. Le nombre de sous-types antigéniques associés à des épizooties domestiques est limité par comparaison à la diversité des virus grippaux $A$ isolés chez les oiseaux sauvages (malades ou porteurs sains). Le réservoir de virus grippaux chez les porcs joue un rôle important dans le risque de transmission des virus aviaires à l'homme. En effet, les cellules épithéliales du tractus respiratoire du porc co-expriment les récepteurs glucidiques (acides sialiques) des virus grippaux humains mais aussi aviaires.
Lors de la pandémie grippale majeure de 1918 (virus HINl responsable de la grippe «espagnole» à l'origine de 20 à 40 millions de morts), il semble que le virus ait été transmis directement des espèces aviaires à l'homme. En effet, il s'agit d'un virus dont la séquence semble d'origine uniquement aviaire, sans trace de réassortiment avec une autre souche virale. II semble également qu'il soit particulièrement virulent, comme le souligne un travail récent démontrant une forte létalité après inoculation chez l'œuf embryonné de poulet et la souris, même s'il n'existe pas de corrélation parfaite entre pathogénicités murine et humaine. II a également été montré que ce virus avait acquis la capacité de se lier aux acides sialiques humains.

Dans les pandémies de 1957 (H2N2, grippe asiatique responsable de 4 millions de morts) et de 1968 (H3N2, grippe de Hong Kong responsable de 2 millions de morts), le virus transmis à l'homme a été le résultat d'un réassortiment génétique entre des segments génomiques de virus aviaires et humains chez le porc, lequel a conduit à un virus associé à une moindre mortalité chez l'homme. La réapparition du sous-type HINl responsable d'une pandémie humaine en 1977 reste inexpliquée. Notamment, le virus n'est pas particulièrement proche de celui isolé à plusieurs reprises chez le porc et responsable, depuis 1918, de nombreux cas d'infections respiratoires dans cette espèce ainsi que de rares cas humains de gravité modérée.

Le phénomène nouveau et important est l'apparition, depuis 1997, de cas isolés d'infections humaines liées à un virus $\mathrm{H} 5 \mathrm{Nl}$ aviaire dans la région de Hong Kong et depuis dans d'autres pays d'Asie chez des personnes ayant une exposition répétée à des volailles domestiques infectées.

Le risque actuel de pandémie peut être lié à la capacité de ce virus aviaire $\mathrm{H} 5 \mathrm{Nl}$ de présenter des mutations progressives d'adaptation permettant une sélection d'un virus à plus grande capacité de transmission inter-humaine, sans étape de réassortiment avec un virus humain tel que cela a été observé pendant la pandémie de 1918. Les mutations d'adaptation peuvent se faire au niveau du site récepteur (RBS, receptor-binding site) de l'hémagglutinine, différent entre les virus aviaires et humains et en partie responsable de la barrière d'espèce. Aucune démonstration d'une telle adaptation n'a pour l'instant été mise en évidence, c'est-à-dire que les virus $\mathrm{H} 5 \mathrm{Nl}$ actuellement isolés chez l'homme restent porteurs d'un site de fixation au récepteur cellulaire de type aviaire. Le risque de pandémie peut également être lié à un réassortiment entre un virus aviaire et un virus humain tel que cela a été observé lors des deux dernières pandémies à partir du réservoir porcin. Ce réassortiment peut aussi se produire chez l'homme 
infecté par les virus grippaux classiques $\mathrm{HIN1}$ et H3N2 et co-infecté par un virus aviaire, d'où la proposition de renforcer la vaccination antigrippale contre la souche grippale épidémique humaine annuelle pour limiter ce risque (et qui contient cette année pour l'hémisphère nord des antigènes viraux de souches $A H I N 1$ et H3N2 ainsi que d'une souche B).

\section{Quelle est l'épidémiologie mondiale de l'épizootie aviaire aujourd'hui ?}

Les épidémies d'infections liées à des virus aviaires hautement pathogènes étaient relativement rares jusqu'en 1990. En 1997, un virus $\mathrm{H} 5 \mathrm{Nl}$ hautement pathogène dans les espèces aviaires a été isolé chez des volailles d'élevage à Hong Kong. Entre 1997 et 2002, ce virus a été isolé à Hong Kong, en Corée du Sud et en Chine.

En 2003, une épidémie d'infection aviaire est également survenue aux Pays-Bas liée à un virus H7N7 avec plusieurs dizaines de cas humains, principalement sous forme de conjonctivites. Un décès humain est survenu. Une plus petite épidémie liée à un virus H7 est survenue en Colombie britannique en 2004 avec un faible retentissement chez l'homme.

Fin 2003 et en 2004, le virus H5Nl a disséminé dans plusieurs pays d'Asie créant une épizootie aviaire majeure (Corée du Sud, Vietnam, Japon, Thaïlande, Cambodge, Hong Kong, Laos, Chine, Malaisie, Indonésie). En Thaillande, $56 \%$ des volailles infectées sont des poulets et $27 \%$ des canards, principalement dans le centre nord et l'est du pays; les canards domestiques peuvent jouer le rôle de réservoirs silencieux du virus hautement pathogène. Le virus $\mathrm{H} 5 \mathrm{Nl}$ a été également isolé dans d'autres espèces animales comme les chats domestiques, les tigres et léopards, probablement suite à l'ingestion de carcasses fraîches de volailles.

La Fédération de Russie a signalé l'infection de volailles en juillet 2005 et la maladie a ensuite été signalée au Kazakhstan en août 2005. Des oiseaux sauvages infectés ont été retrouvés morts dans ces deux pays. La Mongolie a également détecté du virus $\mathrm{H} 5 \mathrm{Nl}$ chez des oiseaux migrateurs retrouvés morts. En octobre 2005, la présence du virus $\mathrm{H} 5 \mathrm{Nl}$ a été détectée et confirmée chez des volailles en Turquie et en Roumanie, à proximité de sites connus comme halte d'oiseaux migrateurs venant du nord-est de ces pays. Une surveillance des oiseaux migrateurs est donc désormais réalisée ainsi que des analyses virologiques en cas de morts suspectes d'oiseaux.

Lorsqu'un foyer de grippe aviaire domestique est identifié, une mise en quarantaine est effectuée ainsi que l'abattage des animaux infectés et exposés. Ainsi, plus de 150 millions de volailles ont été sacrifiés depuis le début de l'épizootie à $\mathrm{H} 5 \mathrm{Nl}$ en Asie avec un retentissement économique important dans les pays concernés. II est également demandé aux éleveurs d'éviter les contacts entre volailles et porcs afin de diminuer le risque de réassortiment génétique.

\section{Quelle est l'épidémiologie de l'infection humaine par le virus H5N1 aujourd'hui?}

De manière générale, les épizooties aviaires récentes se sont accompagnées d'un faible risque de transmission à l'homme avec un risque encore plus faible de transmission inter-humaine. Les cas humains rapportés avec les autres virus que le $\mathrm{H} 5 \mathrm{Nl}$ ont été le plus souvent sans gravité particulière, ce qui contraste avec la sévérité des cas asiatiques liés au $\mathrm{H} 5 \mathrm{Nl}$.

En 1997, le virus H5N1 hautement pathogène dans les espèces aviaires a été isolé chez des volailles d'élevage à Hong Kong avec apparition de 18 cas humains dont 6 sont décédés. Entre 1997 et 2002, le virus a été isolé à Hong Kong, en Corée du Sud et en Chine. En février 2003, ce même virus a été isolé chez 3 membres de la même famille séjournant dans le sud de la Chine en provenance de Hong Kong avec deux décès.

En date du 9 novembre 2005, selon l'OMS, un total de 125 cas humains confirmés d'infection à $\mathrm{H} 5 \mathrm{Nl}$ dont 64 mortels sont survenus principalement au Vietnam, mais aussi en Thaïlande, au Cambodge et, plus récemment, en Indonésie. Les seuls cas de grippe aviaire survenus depuis l'été 2005 proviennent d'Indonésie, le premier patient atteint étant décédé le 12 juillet.

II importe cependant d'insister sur l'importante barrière d'espèce pour le virus $\mathrm{H} 5 \mathrm{Nl}$ expliquant le faible nombre de cas humains rapporté en comparaison à l'importance de l'extension de l'épizootie en Asie. La transmission inter-humaine de l'infection reste aujourd'hui tout à fait exceptionnelle et probablement la conséquence d'un inoculum particulièrement élevé qui permet alors de forcer la barrière d'espèce, les cas groupés familiaux correspondant à une exposition aviaire commune. La contamination se fait principalement au contact de fientes de volailles domestiques infectées, notamment lors du plumage des animaux. D'autres situations sont considérées comme à risque, telles que les visites de poulaillers et la manipulation de carcasses aviaires infectées. La consommation de volailles bien cuites ne pose aucun problème, car le virus ne survit pas à une température de $70^{\circ} \mathrm{C}$. II ne semble pas exister aujourd'hui de formes asymptomatiques de l'infection chez des sujets contacts de patients infectés par le virus $\mathrm{H} 5 \mathrm{Nl}$. Le risque d'infection humaine dans les conditions actuelles semble donc faible, mais la létalité est extrêmement élevée, voisine de 50 \%. Par comparaison, la mortalité humaine de la souche de 1918 avoisinait les 2-4\%, et une souche épidémique humaine classique est associée à une mortalité de moins de 1 pour mille.

\section{Quelles sont les manifestations cliniques de la grippe humaine liée au virus $\mathrm{H} 5 \mathrm{~N} 1$ ?}

Une mise au point récemment parue permet de retenir les caractéristiques suivantes: I'incubation chez l'homme de la pathologie associée au virus aviaire H5Nlest éventuellement plus prolongée que la grippe humaine commune, allant de 2 à 4 jours avec un maximum de 8 à 17 jours. Les sujets frappés ont été pour la plupart des enfants et des jeunes adultes en bonne santé. Un tableau diarrhéique peut précéder les manifestations respiratoires avec la présence de virus dans les selles. Les signes d'atteinte respiratoire basse liées au virus (toux et dyspnée) sont plus précoces que dans la grippe commune et ne sont pas liés à 
une surinfection bactérienne. Des signes d'atteinte du système nerveux central ont été rarement signalés. La présence de lésions inflammatoires dans les poumons des patients décédés suggère que l'importance de la réponse immunitaire de l'hôte pourrait être potentiellement délétère. Une lymphopénie sanguine est souvent rencontrée.

\section{Quels sont les moyens thérapeutiques actuels contre la grippe aviaire?}

II faut insister sur la nécessité de détecter et d'isoler de manière appropriée les cas importés, mais aussi de prendre en charge de manière appropriée les sujets contacts. Une quantité importante de médicaments antiviraux de la classe des inhibiteurs de la neuraminidase a d'ores et déjà été acquis par les autorités de santé en France pour combattre une situation pandémique. Pour des raisons stratégiques évidentes et compte tenu de l'absence d'indication actuelle de ces traitements, ceux-ci sont stockés par le service de santé des armées et ne sont donc pas disponibles à l'heure actuelle pour le grand public. Quatre millions de traitements en gélules et 10 millions en poudre conditionnée d'oseltamivir (Tamiflu ${ }^{\circledR}$ ) seront prochainement disponibles ainsi que 200000 traitements par le zanamivir $\left(\right.$ Relenza $\left.^{\oplus}\right)$. En cas de nécessité, ces traitements seraient administrés gratuitement aux patients. II importe de comprendre que l'efficacité de ces médicaments est d'autant plus grande que ceux-ci sont administrés précocement après exposition. Ils ne semblent pas efficaces au-delà de 48 heures post-exposition. Les souches de virus $\mathrm{H} 5 \mathrm{Nl}$ restent sensibles aux médicaments antiviraux actuels, mais une altération de sensibilité sous traitement a été récemment rapportée. L'intérêt de ces traitements antiviraux dont l'utilisation massive serait à l'évidence associée à la sélection de mutants résistants avec un risque d'inefficacité thérapeutique ultérieure serait d'attendre la mise à disposition d'un vaccin efficace sur la souche pandémique. Il importe aussi de prendre en compte le risque de surinfection bactérienne, notamment par le pneumocoque chez les sujets fragiles et d'insister sur l'importance de la vaccination anti-pneumococcique préventive dans les populations cibles et le recours à une antibiothérapie en cas de grippe sévère déclarée.

Dans les prochains mois, plusieurs millions de masques adaptés seront également disponibles en premier lieu pour le personnel de santé : 50 millions de masques chirurgicaux et 200 millions de masques à haute protection ont déjà été acquis par les autorités de santé en France.

Plusieurs vaccins contre le virus H5NI sont développés par les firmes Sanofi-Pasteur et Chiron, mais ne sont pas encore au stade de la production commerciale. Deux millions de doses ont cependant été commandées en France et 40 millions de doses ont été réservées en cas de pandémie. II faut rappeler que le vaccin antigrippal habituel n'a aucune efficacité préventive contre la grippe aviaire et que le vaccin pandémique ne pourrait être disponible que plusieurs mois après la mise en évidence du virus responsable de celle-ci.

\section{En conclusion}

Afin de minimiser le risque de pandémie, il importe de contrôler de manière urgente l'épizootie aviaire, notamment dans les régions où la densité de population humaine est particulièrement importante et de tenter de renforcer la vaccination antigrippale dans la population mondiale afin de limiter le risque de réassortiment génétique entre virus aviaires et virus humains directement chez l'homme. Le suivi de l'infection chez les oiseaux sauvages et dans les élevages porcins est également fondamental. Pour les voyageurs se rendant actuellement dans les zones d'endémie de grippe aviaire, il faut proscrire les contacts étroits avec les oiseaux malades ou décédés, mais aucune limitation de la consommation de volaille cuite n'est recommandée. Différents plans de lutte contre une pandémie de grippe ont été élaborés dans une quarantaine de pays pour tenter de diminuer au maximum l'impact d'une nouvelle pandémie, mais seul un petit nombre s'est parfaitement bien préparé à ce risque international qui, de toutes les façons, dépassera toutes les capacités de réactivité des systèmes de santé, même ceux des plus performants. $\diamond$

Avian flu: possible implications for human health

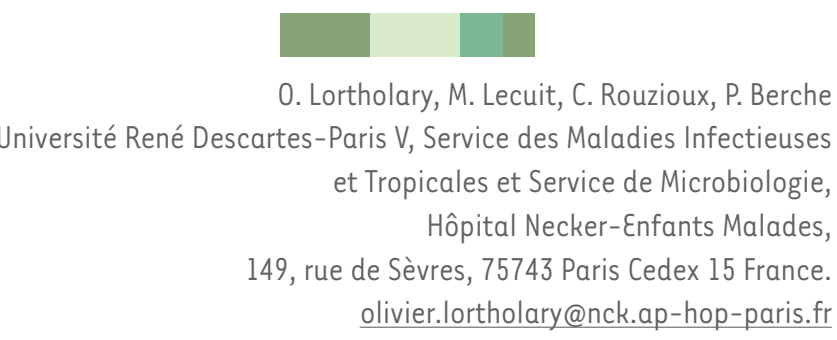

\section{RÉFÉRENCES}

1. Gamblin SJ, Haire LF, Russell RJ, et al. The structure and binding properties of the 1918 influenza haemagglutinin. Science 2004 ; 303 : 1838-42.

2. Li KS, Guan Y, Wang J, et al. Genesis of a highly pathogenic and potentially pandemic $\mathrm{H} 5 \mathrm{NI}$ influenza virus in eastern Asia. Nature $2004 ; 430: 209-13$.

3. Koopmans M, Wilbrink B, Conyn M, et al. Transmission of H7N7 avian influenza A virus to human beings during a large outbreak in commercial poultry farms in the Netherlands. Lancet $2004 ; 363: 587-93$.

4. Kaye $D$, Pringle $C R$. Avian influenza viruses and their implication for human health. Clin Infect Dis 2005 ; 40 : 108-12.

5. Beigel JH, Farrar J, Han AM. Avian influenza A ( $\mathrm{H} 5 \mathrm{N1})$ infection in humans. N Engl J Med $2005 ; 353$ : 1374-85.

6. Le QM, Kiso M, Someya K, et al. Avian flu : isolation of drug-resistant $\mathrm{H} 5 \mathrm{~N} 1$ virus. Nature $2005 ; 437$ : 1108

7. Taubenberger JK, Reid AH, Lourens RM, et al. Characterization of the 1918 influenza virus polymerase genes. Nature $2005 ; 437: 889-93$.

8. Tumpey TM, Basler CF, Aguilar PV. Characterization of the reconstructed 1918 Spanish influenza pandemic virus. Science $2005 ; 310: 77-80$.

9. Tiensin T, Chaitaweesub P, Songserm T. Highly pathogenic avian influenza H5N1, Thailand, 2004. Emerg Infect Dis 2005 ; 11 1664-72. 


\section{Ateliers de formation 2006}

Renseignements et inscriptions :

Ateliers de formation Inserm

101, rue de Tolbiac

75654 Paris Cedex 13

Tél. : 33 (0) 144236203 - Fax : 33 (0) 144236293

ateliers@tolbiac.inserm.fr
Inserm

Institut national

de la santé et de la recherche médicale

\title{
Atelier de formation $n^{\circ} 166$
}

\section{Identification de régions non codantes fonctionnelles dans les génomes}

\author{
Organisateurs : Daniel Gautheret (TAGC Inserm ERM206, Université de la Méditerranée, Marseille), \\ Hugues Roest Crollius (CNRS8541, Ecole Normale Supérieure, Paris)
}

\section{Phase I • Le point sur... 27-28 avril 2006 - La Londe-les-Maures (Toulon)}

\begin{abstract}
Objectifs - L'information génétique contenue dans les génomes eucaryotes est traditionnellement vue comme composée essentiellement des gènes codant les protéines, additionné de quelques ARN non-codant et de régions contrôlant la régulation de ces éléments transcrits. Or des avancées majeures, issues de la génomique fonctionnelle, de la bioinformatique et de la comparaison de génomes, modifient profondément cette vision. Au cours de la vie cellulaire, l'ADN chromosomique est en fait transcrit dans sa grande majorité, et produit de manière reproductible de nombreuses formes d'ARN de nature encore inconnue, en plus des traditionnels ARN messagers, dont la complexité est par ailleurs beaucoup plus importante qu'anticipée initialement. ARN anti-sens, microARN, transcrits multi-exoniques non codants, ces molécules dont l'existence est confirmée par plusieurs techniques expérimentales, sont également pour beaucoup conservées au cours de l'évolution. D'autres éléments «ultra » conservés entre des espèces parfois distantes, susceptibles de jover un rôle important dans la régulation des gènes, posent également de nombreuses questions. L'Atelier sera l'occasion de faire un état des lieux, à l'échelle des génomes eucaryotes, des différents éléments fonctionnels non codants découverts récemment, et des méthodes expérimentales et bioinformatiques qui permettent de les mettre en évidence. Les discussions porteront aussi sur les hypothèses proposées quant au rôle de ces éléments.
\end{abstract}

Public - Chercheurs, bioinformaticiens, post-doctorants, doctorants, ingénieurs s'intéressant aux domaines de la génomique, de la génétique et de l'évolution moléculaire.

Les conférences seront données en anglais.

Nombre maximum de participants : 80

Programme - Les conférences porteront sur les méthodes qui permettent de détecter les éléments fonctionnels non codants dans les génomes : alignements entre séquences génomiques de différentes espèces pour la détection d'éléments conservés, puis exploitation de la structure ou de la transcription (tiling arrays, séquençage d'ADNc) pour la détection d'ARN noncodants. Les aspects statistiques des recherches de motifs seront également abordés. Le contexte biologique de ces éléments sera illustré par des exemples comme le rôle des ARNnc dans le développement embryonnaire, ou leurs conséquences sur l'étude du polymorphisme dans la population humaine.

Avec la participation de - Alex Bateman (Cambridge, Grande-Bretagne), Gill Bejerano (Santa Cruz, Etats-Unis), Mathieu Blanchette (Montréal, Canada), Manolis Dermitzakis (Cambridge, Grande-Bretagne), Tom Gingeras (Santa Clara, EtatsUnis), Ivo Hofacker (Vienne, Autriche), Manolis Kellis (Cambridge, Etats-Unis), Richard Lavery (Paris, France), Graziano Pesole (Milan, Italie), Sophie Schbath (Jouy-en-Josas, France), François Spitz (Genève, Suisse), Peter Stadler (Leipzig, Allemagne), Jacques van Helden (Bruxelles, Belgique).

\section{Phase II • Maîtrise technique}

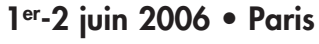

Programme - Application, sur des régions spécifiques ou choisies par les participants, de différents outils bioinformatiques permettant de découvrir et caractériser des éléments fonctionnels non codant dans les génomes eucaryotes (ARN structuraux, motifs d'ADN rares ou fréquents, régions conservées au cours de l'évolution).

Sélection • 12 candidats seront sélectionnés parmi les participants de la phase I. 